\title{
Impact of urbanization on the state of water bodies and adjacent territories
}

\author{
Valentina Kurochkina ${ }^{1, *}$ \\ ${ }^{1}$ Moscow State University of Civil Engineering, 26, Yaroslavskoye Shosse, 109377, Moscow, Russia
}

\begin{abstract}
The processes of urbanization of the territory of the Russian Federation lead to the growing impact of man-made factors on water bodies, especially in those cases when water bodies are located directly in the centers of urbanization, or in the zones of their influence. For water supply of economic activities, a significant proportion of river runoff is withdrawn, large volumes of untreated or conditionally clean wastewater are discharged into rivers. As a result of these processes, the hydrochemical and hydrological regimes of water bodies in urbanized areas have been greatly changed, which in turn leads to the accumulation of a significant amount of contaminated bottom sediments in water bodies, which negatively affects the quality of water and the general ecological state of water bodies. Since the negative impact of urbanization on water bodies with varying degrees of intensity has been going on for over 100 years, the volumes of contaminated sediments accumulated in water bodies, in some cases, reach critical values. Cleaning up contaminated areas of water bodies can be carried out using various sets of measures. However, the development of such measures can only be based on a detailed survey of water bodies. This paper shows that when carrying out such studies, it is necessary to take into account not only the migration of toxic substances in various adjacent environments, for example, from water to bottom sediments, from soils to plants, but also the effect of these compounds on the entire trophic chain, at the end of which there is a person. At the same time, it is necessary to note that both during the restoration work and during the operation of water bodies, it must be remembered that a water body is a single water ecosystem, a system inextricably linked with the adjacent territories.
\end{abstract}

\section{Introduction}

The rate of negative impact of urbanization on water bodies is growing with the growth of the urban population, industry and water transport [1]. The high population density and significant industrial potential contribute to the fact that urbanized areas are becoming the predominant sources of water pollution. Urbanization of territories and the long-term use of

\footnotetext{
* Corresponding author: kurochkina@mgsu.ru
} 
water bodies led to a gradual change in natural conditions and the natural regime of river beds under the influence of technogenic load (Fig. 1).

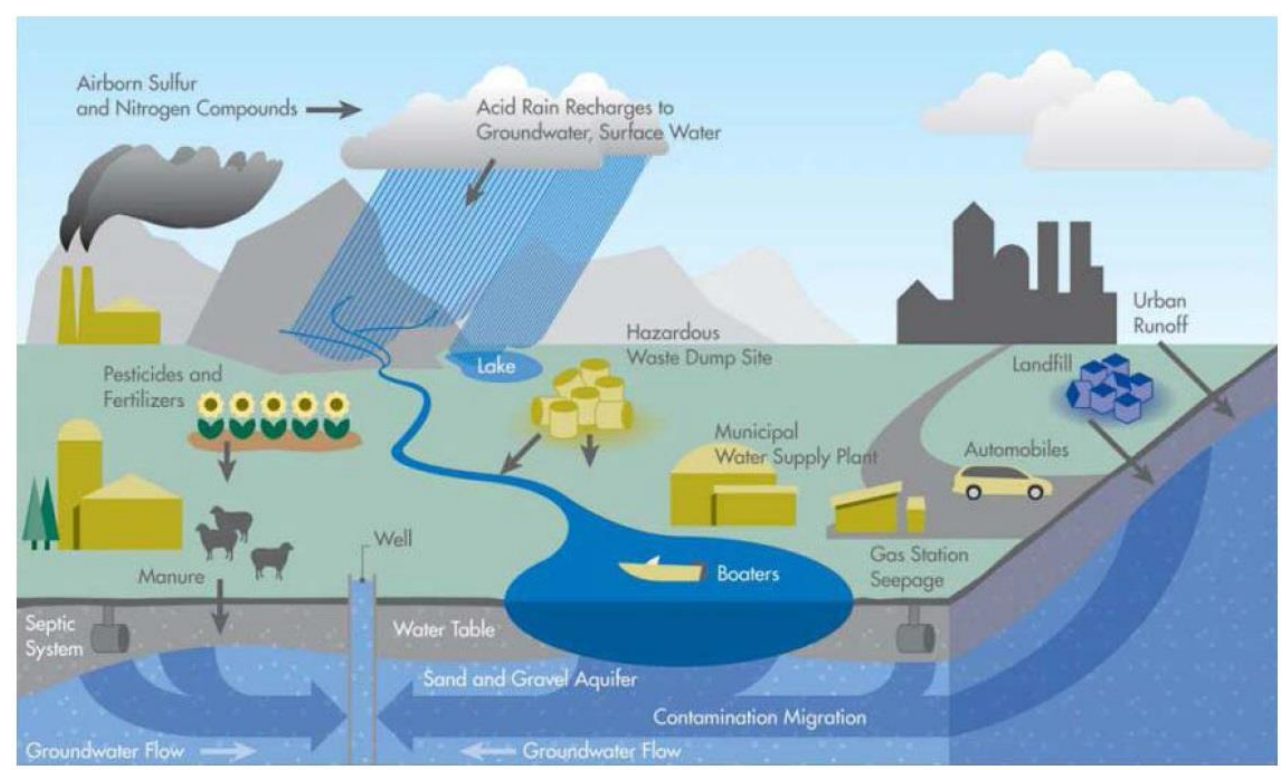

Fig. 1. Influence of anthropogenic load on the state of water bodies and adjacent territories [2].

River systems of urban agglomerations are used for water supply, sewerage, for the needs of water transport and energy, as well as recreational facilities [3-5]. The high population density and significant industrial potential contribute to the fact that urbanized areas are becoming the predominant sources of water pollution (Fig. 2).

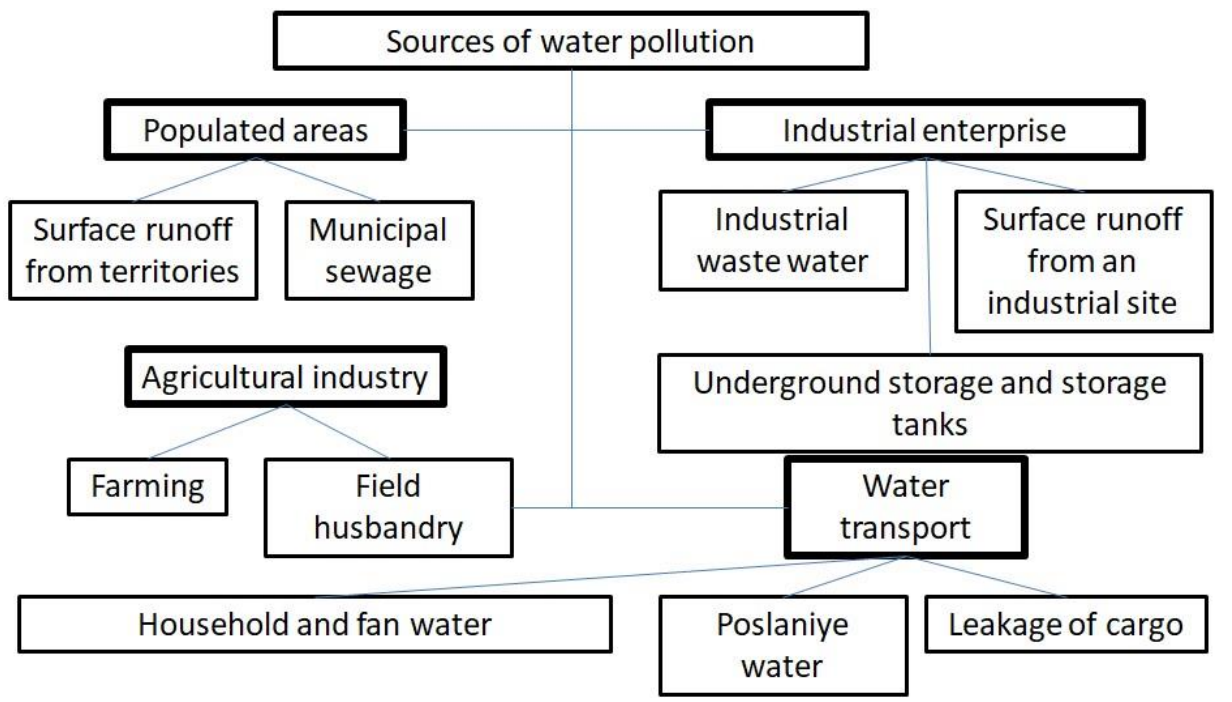

Fig. 2. Sources of water pollution.

The largest consumption of water resources is carried out by enterprises in the energy, chemical, pulp and paper, and metallurgical industries. 
Among the main types of technogenic pollution on the environment, one can single out physical and mechanical pollution; chemical pollution and biological pollution (Fig. 3). Nowadays, other types of pollution are also emitted, for example, such as aesthetic.

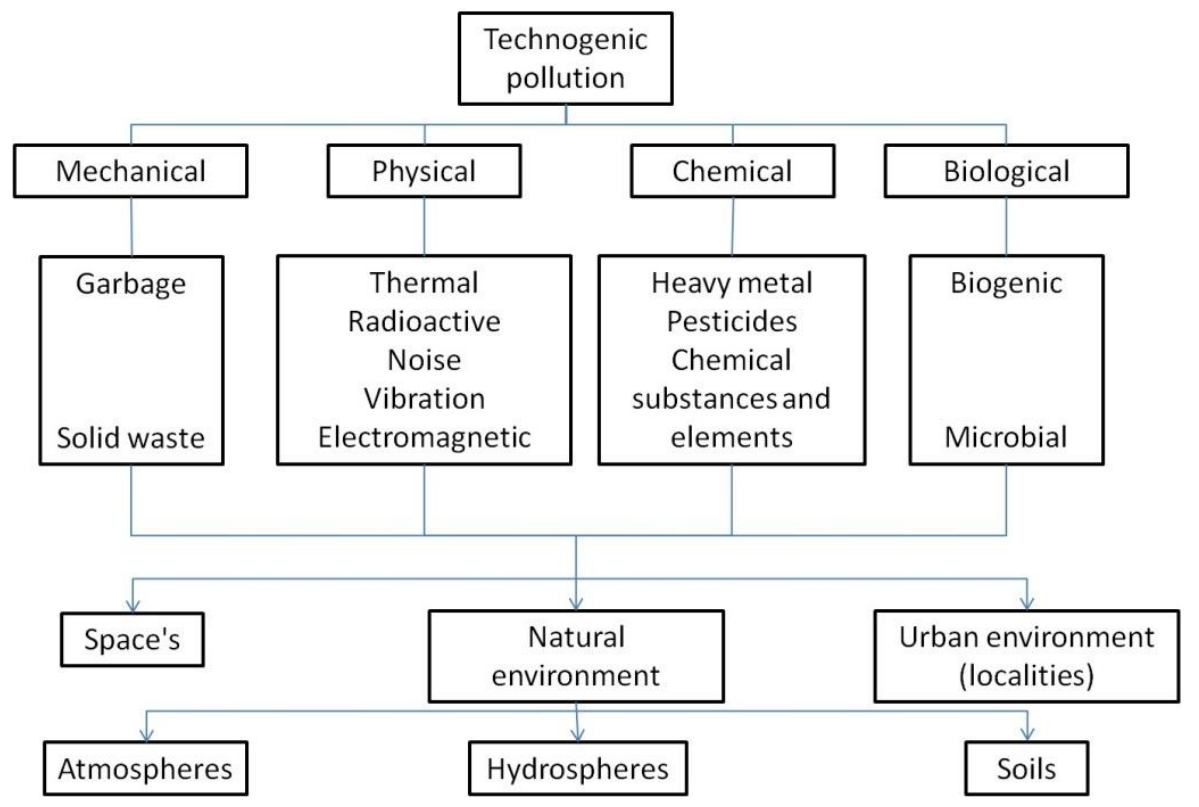

Fig. 3. The main types of technogenic pollution of the environment.

The volume and significance of this problem can be illustrated by the following figures: on the territory of Russia, there are about 3 million lakes, about 1000 large reservoirs, the total area of the water surface is 11.9 million hectares, over 100 thousand artificial ponds, 3 million small rivers. A significant part of these water bodies has been subjected to technogenic impact, silted up, polluted and requires cleaning [1]. The increasing rates of urbanization are characterized by the increasing intensity of anthropogenic impact on water bodies, which has led to the need to create a regulatory system for managing the quality of natural resources [6-10].

\section{Materials and methods}

The removal of suspended matter from urbanized areas can be many times higher than their volume entering a water body from natural landscapes of the same area. The main pollutants include:

- pollution with oil and oil products, this is typical of most urban water bodies,

- chloride pollution associated with the use of salts that simulate snow melting,

- PAH contamination (especially benzo(a)pyrene, which is especially intensively supplied from surface runoff),

- pollution with detergents, which can cause a violation of the oxygen regime, a change in the natural course of chemical processes, poisoning of aquatic organisms and oppression of life in water bodies,

- pollution with heavy metals, the danger of pollution with which is associated with the concentration function of organisms, specifically, when moving from water to aquatic vegetation, the concentration of pollutants increases as they move along trophic links $[11,12]$. 
The nature of the effect of certain substances on human health is shown in Table 1 .

Table 1. The influence of certain chemical elements on human health.

\begin{tabular}{|l|l|}
\hline \multicolumn{1}{|c|}{ Element } & \\
\hline $\mathrm{Ni}^{2+}$ & damage to kidney \\
\hline $\mathrm{Cd}^{2+}$ & carcinogen damage to the kidneys, lungs, skin \\
\hline $\mathrm{C} \Gamma 3+$ & deficiency leads to atherosclerosis \\
\hline $\mathrm{Cu}^{2+}$ & damage to the gastrointestinal tract \\
\hline $\mathrm{Pb}^{2+}$ & damage to the hematopoietic system \\
\hline $\mathrm{Hg}^{2+}$ & damage to central nervous system \\
\hline $\mathrm{Zn}^{2+}$ & toxic \\
\hline $\mathrm{As}^{3+}$ & skin cancer \\
\hline $\mathrm{Se}^{6+}$ & toxic \\
\hline $\mathrm{Be}^{: "}$ & damage to the hematopoietic system, nerve cells of the brain \\
\hline $\mathrm{Mo}^{6+}$ & "molybdenum gout" \\
\hline $\mathrm{Mr}^{2+}$ & damage to central nervous system \\
\hline
\end{tabular}

On admission to water bodies, contaminants are distributed between the components of the aquatic ecosystem [13]. Forming complex compounds, they may exhibit migratory properties to a greater or lesser extent depending on various factors, the level of organic substances or $\mathrm{pH}$ of the medium, which may vary significantly throughout the year.

The general level of pollution of water bodies can be determined by the following interrelated factors:

- quantitative and qualitative characteristics of pollutants coming from pollution sources

- hydraulic and hydrogeological characteristics of the water body

- composition and properties of contaminated bottom sediments

- secondary pollution

The conditions for the deposition of particles and the formation of bottom sediments, the interaction of water and bottom sediments, the migration and transformation of pollutants in a water body - all these factors will affect the level of pollution of water bodies. The scheme of the impact of pollution on the ecological state of the aquatic ecosystem is shown in Figure 4.

When deposited,man-made pollutants can act as a long-term pollutant of surface waters. At the same time, polluted bottom sediments and vegetation of water bodies can act as a permanent source of pollution of a water body even if the impact that caused the ingress of pollutants into them has been terminated [14].

In order to obtain information about the nature, scale and characteristics of the impact of urbanization on a water body (taking into account the fact that most cities were built on the banks of rivers, influencing the formation of urbanized territoriesto a greater or lesser extent), it is necessary to rely on criteria or indicators, reflecting the following factors:

- features of the formation of the city (identity), which are determined by the history of the formation of the city, the features of development at different stages of the formation of the urban environment, the presence of water bodies;

- location of the center of urbanization in the immediate vicinity of a water body (watercourse) with the determination of the degree of its influence on the formation of an urbanized space;

- formation of the integrity of the urbanized space, of which water bodies are an integral part (harmonious interaction of water areas and adjacent territories);

- different scales of water bodies (streams) and urbanization centers in terms of water content, population and nature of production;

- coverage of various climatic zones of the Russian Federation;

- landscape features of the area; 
- analysis of water bodies with different hydromorphological parameters, including central and small watercourses (identification of the nature of the use of water bodies, the degree of their anthropogenic change, including biota, the level of pollution);

- the possibility of development and transformation of the system "urbanized territory water body"in time at any stage of its existence.

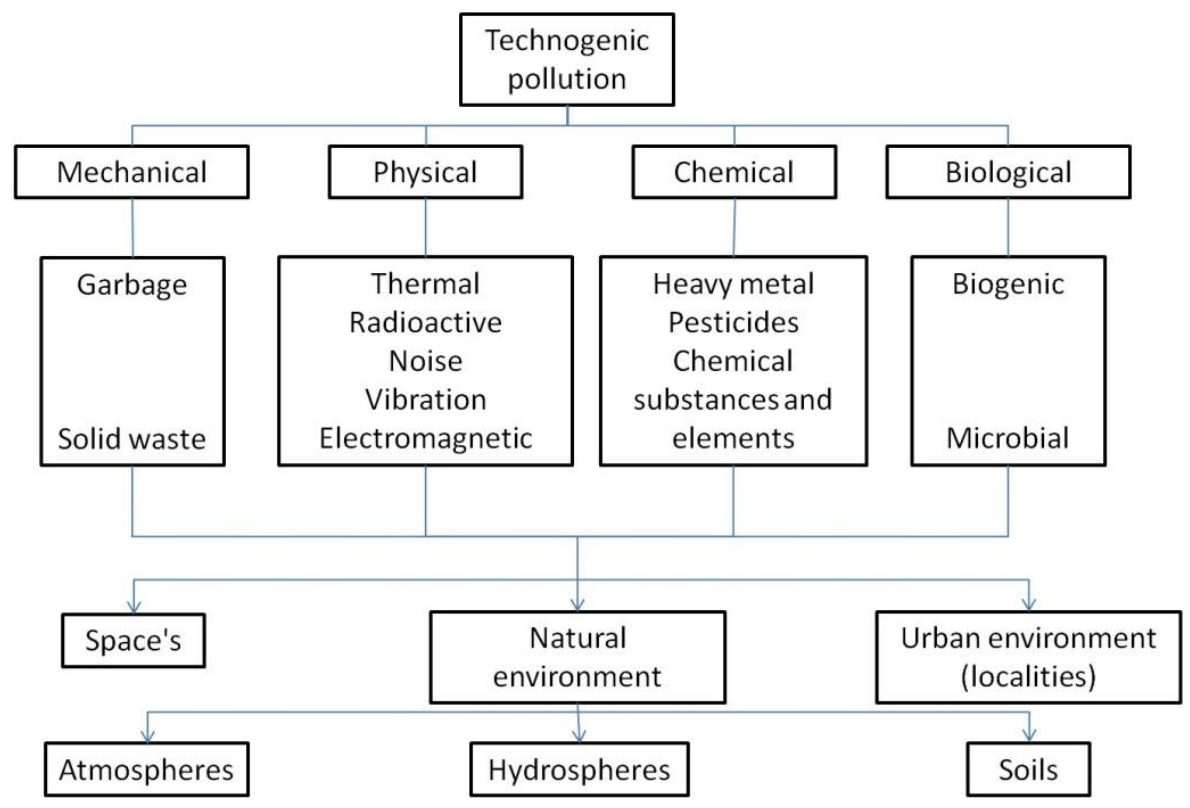

Fig. 4. General scheme of primary and secondary pollution of water bodies.

\section{Research results}

Nowadays, the assessment of the ecological or sanitary-toxicological hazard of the levels of the content of chemical elements in the environment in Russia is carried out by comparing their real concentrations in the studied natural component with the normative levels that determine the safe conditions for the existence of living organisms, primarily humans. For these purposes, the indicators of the existing system of sanitary and hygienic regulation are usually used in Russia (MPC - maximum permissible concentration, APC -approximate permissible concentration, MPL - maximum permissible level, etc.).

To determine the degree of pollution impact on aquatic ecosystems, the concentrations of pollutants in the environment are compared with their maximum permissible concentrations (MPC), the developed and calculated maximum values of the concentrations of pollutants in the environment under consideration, established for a certain period of averaging observations, do not have, when adopted based on the results of experimental observations of the likelihood, any harmful effects on living organisms.

So, for example, for the aquatic environment in Russia, MPCs have been developed as an abiotic component for drinking and technical water supply, as well as for fishery water bodies $\left(\mathrm{MPC}_{\mathrm{fish}}\right)$, and the hygienic assessment of water quality includes an assessment of its organoleptic properties, chemical composition, microflora and microfauna (Fig. 5). 


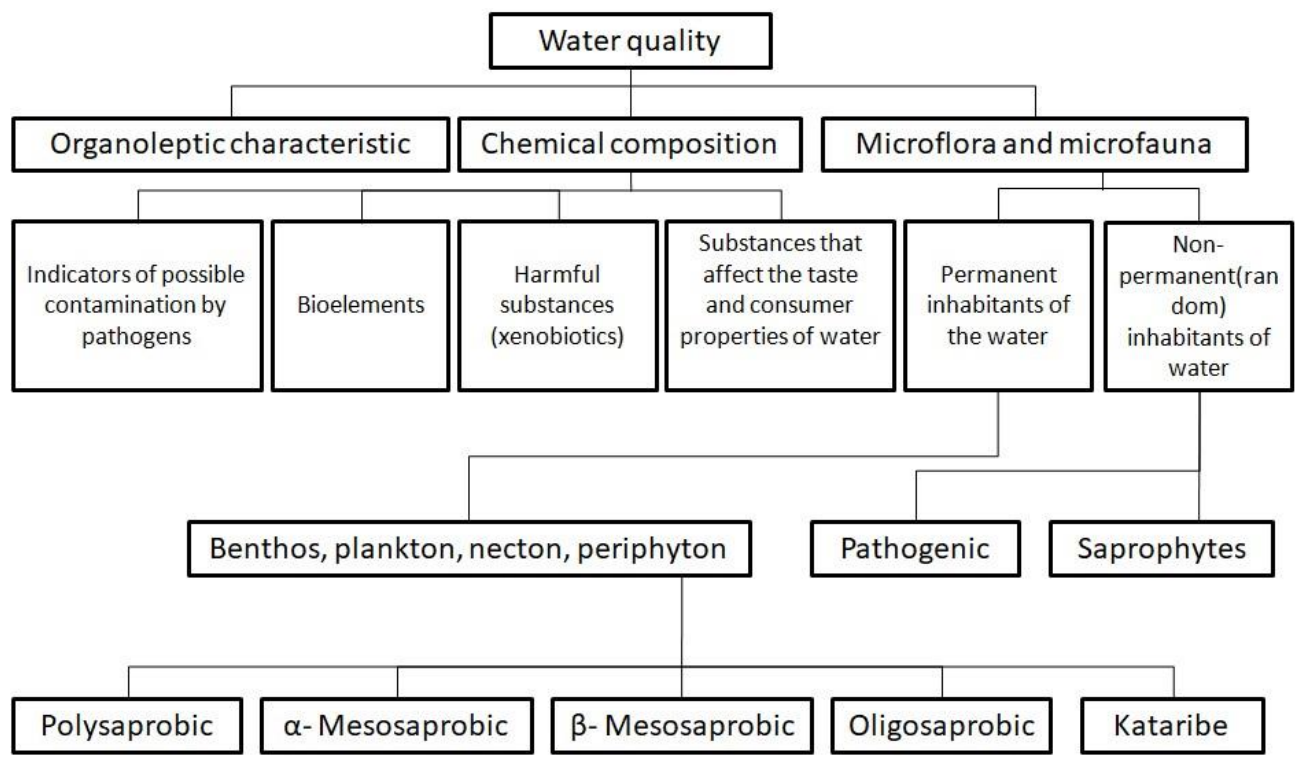

Fig. 5. Factors determining the quality of natural water [15].

Figure 6 shows the results of the analysis of bottom sediments of the Moskva River using such approaches, which showed the presence of toxic compounds, including heavy metals in quantities significantly exceeding the maximum permissible concentration (MPC) [16]. The total content of heavy metals in bottom sediments reaches $1000-15000 \mathrm{mg}$ per $\mathrm{kg}$ of dry weight, which in percentage terms is approximately 100-1000 times higher than the MPC of these compounds in water.

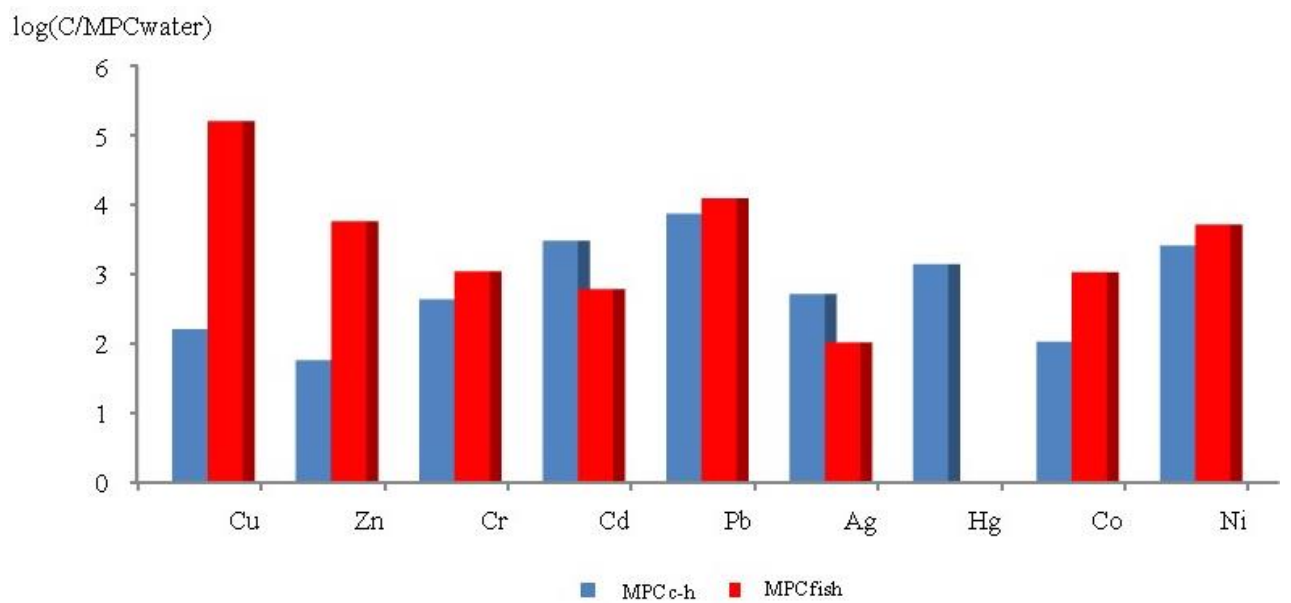

Fig. 6. The ratio of the concentration of heavy metals to the MPC values for water bodies of fishery and cultural and household water use.

However, the used sanitary-toxicological indicators, for the most part used to assess the quality of the respective media, have some disadvantages. So, for example, the existing MPCs do not take into account the dependence of the degree of their impact on living organisms on various conditions [17]. In particular, such assessments do not take into account the fact that the harm caused is determined not by the presence of toxicants, but by their biological availability. Cases of lack of toxicity effect (death of test objects) are 
possible, even if toxicants are detected during chemical analyzes. And, conversely, a harmful effect may appear with a registered absence of toxicants.

In addition, chemical indicators do not take into account the possibility of transformation of pollutants in water and bottom sediments, their interaction. At the present time, a biogeochemical classification performed according to a number of parameters, such as life time, biochemical activity, toxicity, carcinogenicity, etc., seems to be the most complete one. It is presented in Table 2.

Table 2. Classification of HMs by their biogeochemical properties [18]: $\mathrm{H}$ - high, $\mathrm{M}$ - moderate and $\mathrm{L}$ - low level of manifestation of the metal properties.

\begin{tabular}{|c|c|c|c|c|c|c|c|}
\hline Property & Cd & Co & $\mathbf{C u}$ & $\mathbf{H g}$ & $\mathbf{N i}$ & $\mathbf{P b}$ & $\mathbf{Z n}$ \\
\hline Biochemical activity & H & H & H & H & H & H & H \\
\hline Toxicity & H & M & M & H & M & H & M \\
\hline Carcinogenicity & - & H & - & - & H & - & - \\
\hline Enrichment of aerosols & H & L & H & H & L & H & H \\
\hline Mineral form of distribution & H & H & L & H & L & H & L \\
\hline Organic form of distribution & H & H & H & H & H & H & H \\
\hline Mobility & H & L & M & H & L & H & M \\
\hline Bioconcentration trend & H & H & M & H & H & H & M \\
\hline Accumulation efficiency & H & M & H & H & M & H & H \\
\hline Complexing ability & M & L & H & M & L & L & H \\
\hline Hydrolysis tendency & M & L & H & M & - & M & H \\
\hline Solubility & H & L & H & H & - & H & H \\
\hline Lifetime & L & H & H & L & - & L & H \\
\hline
\end{tabular}

The modern ecological assessment of the state of the components of the natural environment should be based on a complex of geochemical, geoecological coefficients and indicators, and the degree of pollution of surface, groundwater, bottom sediments, and soil cover should include various geoecological criteria (hydrogeochemical, geochemical, geophysical, etc.), which can be subdivided into:

- direct criteria for assessing the impact of anthropogenic load on the ecosystem. With their help, it is possible to carry out a quantitative assessment of the components of the environment by various types of pollution for such types of anthropogenic impact as: transformation of the territory, technogenic load, radioactive pollution, agricultural load and the use of natural resources.

- $\quad$ indirect criteria focused on assessing the impact of one environment on adjacent environments with which they interact (for example, "surface water-bottom sediments").

Among the indicators of the state of the environment, we would like to highlight biochemical indicators and soil indicators.

Biochemical indications are based on measurements of abnormalities in the content of chemicals, mainly toxic and trace elements in plants, the impact of which leads to negative physiological and metabolic disorders. Biotesting and bioindication methods make it possible to determine the integral toxicity due to the combination of all toxic chemicals and their metabolites present in the sample $[19,20]$. Biochemical indicators can be aimed at determining both the coefficients of biological absorption by plants and at recording biological indicators of germination and growth rates of plants at different stages of their vegetation.

Soil indicators of the environmental hazard of pollution of such abiotic components as, for example, soils and bottom sediments, which were mentioned above, can be based on an assessment of soil fertility, soil salinity, soil erosion, toxicity, secondary anthropogenic and other processes related to human activities.

The use of geo-ecological approaches and criteria will help to solve such problems as: 
- $\quad$ conducting comprehensive studies of urbanized areas;

- $\quad$ assessment of the state and stability of natural and technical systems;

- development of models of urbanized territories;

- $\quad$ organization of monitoring of natural and technical systems.

Also, the use of an integrated ecological approach in assessing the state of the components of the natural environment can serve to study the transformation processes of landscapes of urbanized territories, to study natural and techno-natural processes and phenomena. This, in turn, can form the basis for recommendations and an action plan aimed at the rational use of water and land resources of water bodies and adjacent territories under the influence of urbanization.

\section{Conclusions}

Based on the analysis of the results presented in the paper, it can be seen that the water bodies of urbanized areas are heavily polluted. So, for example, the analysis of bottom sediments of the Moscow River showed the presence of toxic compounds, including heavy metals in quantities significantly exceeding the maximum permissible concentration, which in percentage terms is approximately 100-1000 times higher than the MPC of these compounds in water. The processes of self-cleaning of media, such as, for example, water, bottom sediments of media are directly related to the problem of migration of pollutants in these media. Therefore, water bodies and adjacent territories constitute a single system, which must be considered together.

The paper analyzes various approaches to standardizing the quality of the media of water bodies and adjacent territories under the influence of urbanization. Based on a comparative analysis of various approaches to the standardization of environments, it can be concluded that, along with the traditional approaches to sanitary and toxicological hazard assessment, one of the most promising approaches for the purpose of standardizing the degree of pollution of various components of the environment is the use of biogeochemical approaches based on the study of migration processes, the distribution of pollutants in the system "bottom sediments - suspended matter - water - biota" of the water body.

It should be noted that biological methods, integrating the characteristics of the load of pollutants, do not always indicate the reasons for the occurrence of biological effects and should be used along with the maximum permissible concentrations.

At the same time, the main advantage of chemical methods remains their relatively easy applicability, studies on a wide range of chemicals, and the fact that they can serve as a basis for various modeling methods.

\section{References}

1. V.I. Telichenko, V.A. Kurochkina, Vestnik MGSU 6, 81-90 (2016) https://lib.rucont.ru/efd/422037

2. Source Water Protection Primer, https://www.safewater.org/fact-sheets1/2017/1/23/source-water-protection

3. A.A. Gorelov, Ecology (Yurayt-M LLC, M., 2002)

4. K.V. Grishanin, The dynamics of channel flows (Gidrometeoizdat, L., 1979)

5. B.M. Dobroumov, Transformation of water resources and the regime of rivers in the ETC center (Gidrometeoizdat, L., 1980) 
6. V.I. Osipov, Geoecology. Engineering geology. Hydrogeology. Geocryology 1, 3-10 (2005)

7. S.N. Cherkinskiy, Sanitary conditions for the discharge of wastewater into water bodies (Stroyizdat, M., 1977)

8. A.P. Lepikhin, Water Industry of Russia 4, 318-345 (2004)

9. A.A. Tranin, Environmental protection: problems of development of bourgeois law (Nauka, M., 1987)

10. A.N. Lebedeva, O.P. Lavrik, Environmental legislation of developed countries (Siberian branch of the State Public Scientific and Technical Library, Novosibirsk, 1991)

11. S.B. Shustov, Chemical foundations of ecology (Education, M., 1995)

12. I.A. Lapin, Oceanology 26(4), 621-627 (1986)

13. T.L. Egoshina, L.N. Shikhova, E.M. Lisitsina, A.S. Zhiryakov, The problem of regional ecology 2, 17-23 (2007)

14. O. Gamayunova, M. Petrichenko, A Mottaeva, Journal of Physics: Conference Series 1614, 012066 (2020) doi:10.1088/1742-6596/1614/1/012066

15. V.I. Narykov, Yu.V. Lizunov, M.A. Bokarev, N28 Water supply hygiene: a tutorial (SpecLit, SPb, 2011) ISBN 978-5-299-00455-7

16. T.G. Bogomolova, V.A. Kurochkina, Vestnik MGSU 2(4), 399-405 (2010)

17. T.I. Moiseenko, Water Resources 26(2), 186-197 (1999)

18. V.V. Voronov, Vestnik of new medical technologies 2(VI), 134-142 (1999)

19. T.V. Izvekova, Biotest analysis is an integral method for assessing the quality of environmental objects (Ivanovo State University of Chemical Technology, 2007)

20. A.A. Pirogova, V.F. Zaraev, D.N. Khamyanov, Yu.G. Borodin, A.G. Perekupka, Oil industry 4, 108-11 (2009) 